\title{
TRAINING OF TEXTILE CREATIVES IN THE FIELD OF E- TEXTILES DESIGN SOFTWARE
}

\author{
DOI: $10.35530 /$ TT.2021.40
}

\section{I.R. Radulescu*, R.M. Aileni, A. Salistean, S. Olaru, M.C. Grosu, R. Scarlat, I. Sandulache}

National Research Development Institute for Textiles and Leather, Romania

(Email: razvan.radulescu@incdtp.ro, raluca.aileni@incdtp.ro, adrian.salistean@incdtp.ro, sabina.olaru@incdtp.ro,_catalin.grosu@incdtp.ro, irina.sandulache@incdtp.ro)

\begin{abstract}
Textile technologies are rapidly developing and coping with the modern software applications of etextile design means a substantial benefit for textile creatives. The target group of textile creatives is considered to include both young professionals in the textile industry as well as students of Higher Education in technical fields. A partnership of six prestigious research and educational providers in Europe, coordinated by INCDTP Bucharest have joined their expertise to offer educational modules related to this need, within the Erasmus+ project "OptimTex- Software tools for textiles creatives". The project has duration of two years (2020-2022) and has already implemented the educational modules in e-learning format on the project's website (www.optimtex.eu). The five educational modules follow the main textile technologies and describe in a Problem-Based-Learning (PBL) approach software applications for: weaving, knitting, virtual prototyping of clothing, embroidery of e-textiles (electronic textiles) and experimental design. The PBL approach consists in learning by examples, followed by the theory, the corresponding software applications and a quiz for selfassessment. The e-learning instrument was programmed in HTML5 and JavaScript and offers quick access the educational modules. INCDTP has conceived the fifth module on experimental design, by tackling plasma treatments of textiles for various functionalities: hydrophobic, hydrophilic and electrical conductivity. Full factorial, Central Composite Design and Fractional factorial experimental design plans were described. This topic is of interest for the envisaged target group, for it represents alternative and useful knowledge to the official curricula of Higher Education engineering studies. Intensive Study Programs and Multiplier events will be organized in the second project's year for students of Higher Education and textile professionals.
\end{abstract}

Keywords: design, e-textiles, e-learning, software, education

\section{INTRODUCTION}

The world-of-work in textiles requires a well-skilled labour force with knowledge of the latest trends in textile technology [1]. Among these latest trends, a special role is represented by the computer software applications for design of e-textiles [2]. As such, a high value-added professional competence is given by the knowledge and skills in software for textiles. The skilled work force has improved chances to find a good work place and to benefit from the value-added competences.

The software applications in e-textiles are grouped on the various textile technologies, such as weaving, knitting, virtual prototyping of clothing, embroidery of e-textiles and experimental design. Since these types of software demand specialists with basic notions of textiles and computer, the process to upskill the competences in this domain is targeted 
towards young professionals from the textile industry as well as by students of higher education. This target group was generically named "textile creatives". The need of improving skills in design software for e-textiles (electronic textiles) was tackled by the Erasmus+ OptimTex project - "Software tools for textile creatives”.

\section{THE ERASMUS+ OPTIMTEX PROJECT}

The Erasmus+ project OptimTex - "Software tools for textile creatives" is a strategic partnership project in the field of Higher Education. It has an implementation period of two years (Dec. 2020 - Nov. 2022) and was funded by the Erasmus+ National Agency in Romania ANPCDEFP. INCDTP - Bucharest coordinates a prestigious partnership formed of research and educational providers in Europe: TecMinho / University of Minho from Portugal, Ghent University from Belgium, University of Maribor from Slovenia, Technical University "Gh. Asachi” from Iasi, Romania and University West Bohemia from Czech Republic. Basic info related to objectives, results and the partnership of OptimTex may be accessed on the project's website www.optimtex.eu . Figure 1 presents the Erasmus+ logo and the project's logo.

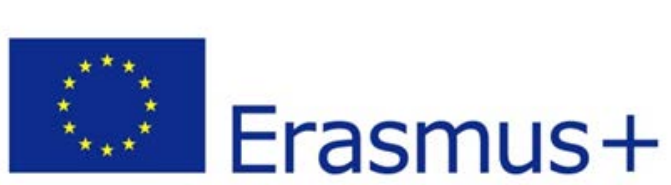

a

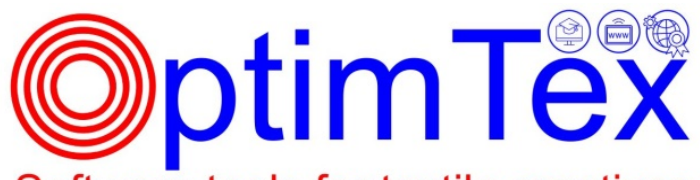

Software tools for textile creatives

b

Figure 1. Images of: a - Erasmus+ logo; b - Project's logo

The educational content was divided in several modules according to the main textile technology domains and the key expertise of the six partners, as follows:

- $\quad$ Design and modelling of woven structures - Ghent University

- $\quad$ Design and modelling of knitted structures - Technical University Iasi

- Design and modelling of garments by 3D scanning software and CAD/PDS software - University of Maribor

- $\quad$ Design and modelling of embroidered structures - University West Bohemia

- $\quad$ Software for research experimental design - INCDTP - Bucharest

The educational modules were conceived of about 40 pages including images and videos. These modules were already accomplished by the project's partners in the first project's year and they form the basic content for the three Intensive Study Programs with students of Higher Education, as well as the six Multiplier events with professionals from the industry. In order to organize these training / multiplier events, the educational modules are going to be implemented in e-learning format on the project's Moodle platform at www.advan2tex.eu/portal/. The Moodle e-learning platform includes already the educational materials of the previous three Erasmus+ VET projects, with open access (figure 2).

\section{THE E-LEARNING INSTRUMENT}

The OptimTex educational modules were already implemented online, by means of an e-learning instrument. The instrument was conceived to enable quick access in a visual and structured manner to the educational modules [3,4]. All the provided modules described examples of software for textiles in a Problem-Based-Learning approach [5,6]. As such, each module included 4-5 examples, completed by the corresponding theory, the required software applications as well as the multiple-choice questions for self-assessment of the acquired 
knowledge. In order to support the learning process, the e-learning instruments provide access to each of these four elements of the educational modules. Please consult figure 3 on the concept of the e-learning instrument with the four HTML buttons: Example, Theory, Application and Quiz.

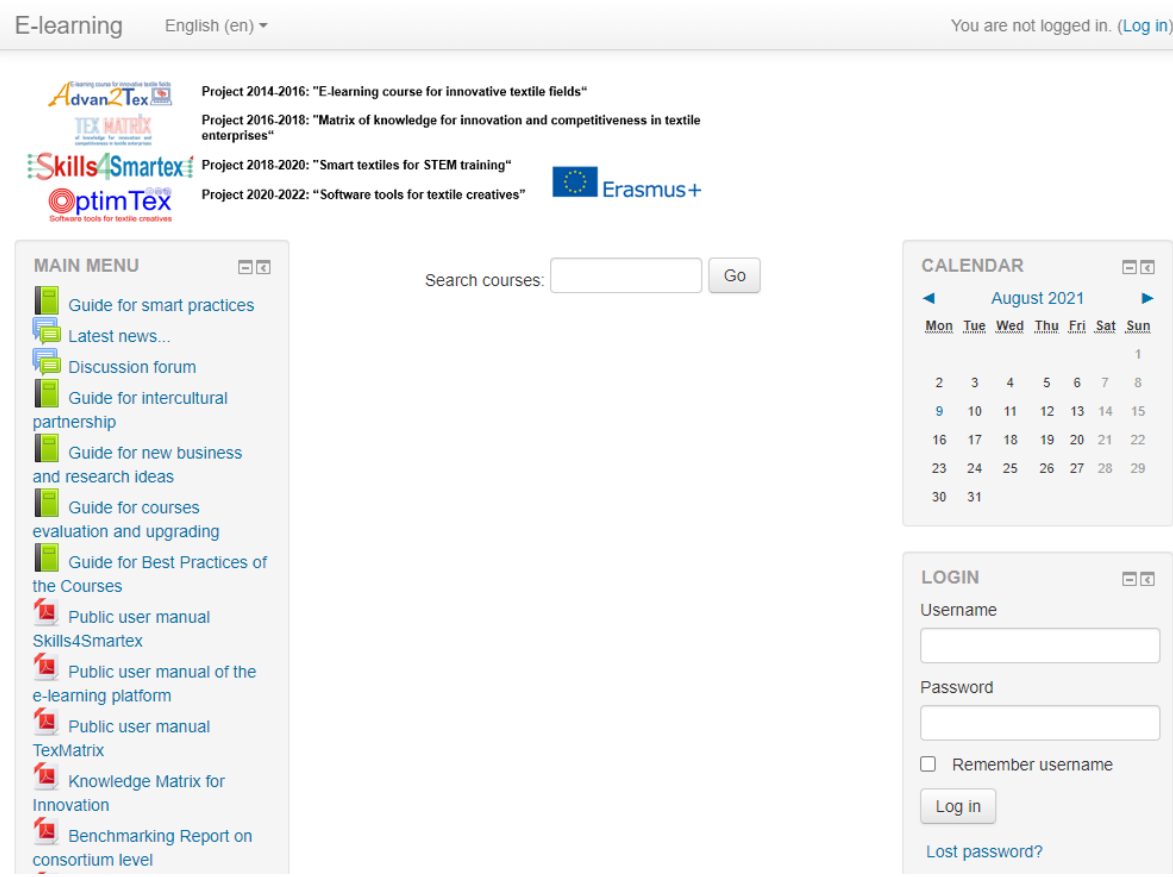

Figure 2. The Moodle e-learning platform

Home About project Partners E-learning Instrument Dissemination Contact

\footnotetext{
OptimTex e-learning instrument

The educational content of OptimTex is divided on 5 modules on software for design of e-textiles:

- Design and modelling of woven structures

- Design and modelling of knitted structures

- Design and modelling of garments by 3D scanning software and CAD/PDS software

- Design and modeling of embroidered structures

- Software for research experimental design
}

Each module is conceived in a Problem-Based-Learning approach and is structured with several practical examples, the corresponding theory, software for design and quiz for self-assessment The e-learning instrument is meant to share quick access on the structured educational content of the Erasmus+ project

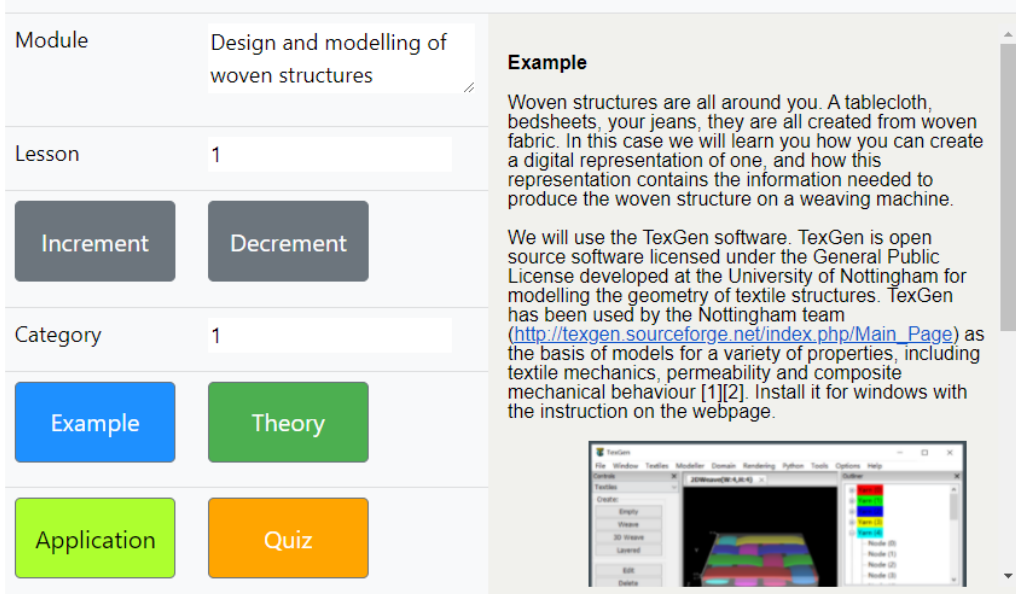

Figure 3. The HTML5 / JavaScript e-learning instrument 
The e-learning instrument was programmed in HTML5 and JavaScript and was included as webpage on the online project's website (www.optimtex.eu). Each of the four elements of an example may be accessed by the corresponding HTML5 button. This modality to present the educational content of the project is in line with the open-access provisions of Erasmus+ EC program and is conceived as well in a Problem-Based-Learning approach.

\section{THE MODULE ON EXPERIMENTAL DESIGN}

INCDTP - Bucharest has prepared the fifth educational module, named "Software for research experimental design". This module tackles by four examples the topic of experimental design and the related software solutions of regression computing. The examples belong to the plasma treatment of textile materials for various functionalities, such as hydrophobic, hydrophilic and electric conductive properties. The used experimental design plans were:

- Full factorial with two input parameters and three variation levels

- Box-Wilson - Central Composite Design with two input parameters and five variation levels

- Full factorial with four input parameters and two variation levels

- Fractional factorial with six input parameters and two variation levels

In order to optimize the plasma treatment on textile materials, several input parameters, such as the power of the generator, the process time, the gas flow and the process pressure have to be simultaneously varied, according to an experimental plan and the corresponding experimental matrix (design phase). A mathematical model, usually a polynomic equation second degree may be associated between the input parameters of the physical process and the result variable and its coefficients computed by regression (analysis phase). This mathematical model may be further used to compute intermediate values by interpolation and to perform the MINMAX analysis for optimizing the result and determine the corresponding input parameters (prediction phase) [7,8].

The first example tackles the hydrophobic plasma treatment by hexafluoro propane gas, on cotton fabrics, by the low-pressure plasma equipment of INCDTP. The power of the generator and the process time were considered as input parameters. The result variable to characterize the hydrophobic functionality was considered the Water Contact Angle (WCA) (figure 5), measured by means of a goniometer equipment (figure 4).

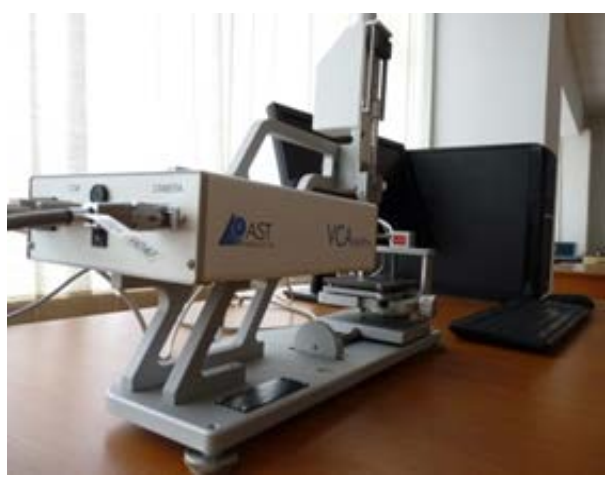

Figure 4. The contact angle instrument

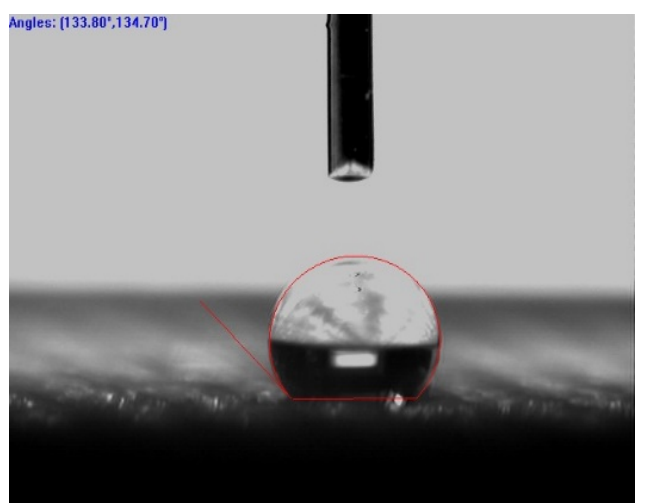

Figure 5. Photo of water droplet on the cotton fabric

The values of the three variation levels of the two input parameters Power and Time are presented in table 1. 
Table 1. The variation levels of the input parameters

\begin{tabular}{|c|c|c|}
\hline Level & Power (W) & Time (min) \\
& $\boldsymbol{x}$ & $\boldsymbol{Y}$ \\
\hline upper: +1 & 30 & 4 \\
\hline medium: 0 & 20 & 3 \\
\hline lower: -1 & 10 & 1 \\
\hline delta $\Delta$ & 10 & \\
\hline
\end{tabular}

The input parameters were encoded by equations 1 and 2, while the mathematical model, the polynomic equation second degree is given by equation 3 .

$$
\begin{gathered}
x=\frac{P-20}{10} \\
y=\frac{t-3}{1} \\
Z=a_{0}+a_{1} x+a_{2} y+a_{12} x y+a_{11} x^{2}+a_{22} y^{2}
\end{gathered}
$$

The experimental matrix of the physical process, with the result variable WCA is

\begin{tabular}{|c|c|c|c|c|c|c|c|}
\hline \multirow{2}{*}{\multicolumn{2}{|c|}{ Sample code }} & \multirow{3}{*}{$\begin{array}{c}\text { Power } \\
\mathbf{X} \\
1 \\
\end{array}$} & \multirow{3}{*}{$\begin{array}{c}\text { Time } \\
\mathbf{y} \\
1 \\
\end{array}$} & \multicolumn{3}{|c|}{ Variables } & \multirow{3}{*}{$\begin{array}{c}\text { Result } \\
\mathbf{Z} \\
138.3 \\
\end{array}$} \\
\hline & & & & \multirow{2}{*}{$\begin{array}{c}\mathbf{X y} \\
1 \\
\end{array}$} & \multirow{2}{*}{$\begin{array}{c}\mathbf{x}^{2} \\
1 \\
\end{array}$} & \multirow{2}{*}{$\begin{array}{c}\mathbf{y}^{2} \\
1 \\
\end{array}$} & \\
\hline $\mathrm{P} 1$ & 1 & & & & & & \\
\hline $\mathrm{P} 2$ & 1 & 1 & 0 & 0 & 1 & 0 & 133.6 \\
\hline P3 & 1 & 1 & -1 & -1 & 1 & 1 & 134.7 \\
\hline $\mathrm{P} 4$ & 1 & 0 & 1 & 0 & 0 & 1 & 135.8 \\
\hline P5 & 1 & 0 & 0 & 0 & 0 & 0 & 137.2 \\
\hline P6 & 1 & 0 & -1 & 0 & 0 & 1 & 128.1 \\
\hline P7 & 1 & -1 & 1 & -1 & 1 & 1 & 135.6 \\
\hline $\mathrm{P} 8$ & 1 & -1 & 0 & 0 & 1 & 0 & 131.6 \\
\hline P9 & 1 & -1 & -1 & 1 & 1 & 1 & 128.4 \\
\hline
\end{tabular}
given by table 2 .

Table 2. The experimental matrix with result variable WCA

The regression computing in EXCEL was used, in order to compute the coefficients of the polynomic equation (figure 6).

This is an example of experimental design in the textile field to serve as educational content for Higher Education students. The software application, such as EXCEL, was applied to support the computational process of regression. The other examples of the course include more software applications with the practical modality to use: MATLAB, MODDE, NCSS, OpenOffice CALC. In this way, we aim to support the textile creatives to improve their knowledge and skills by practical applications. Please consult for the complete set of educational examples the e-learning instrument on the project's website www.optimtex.eu. 

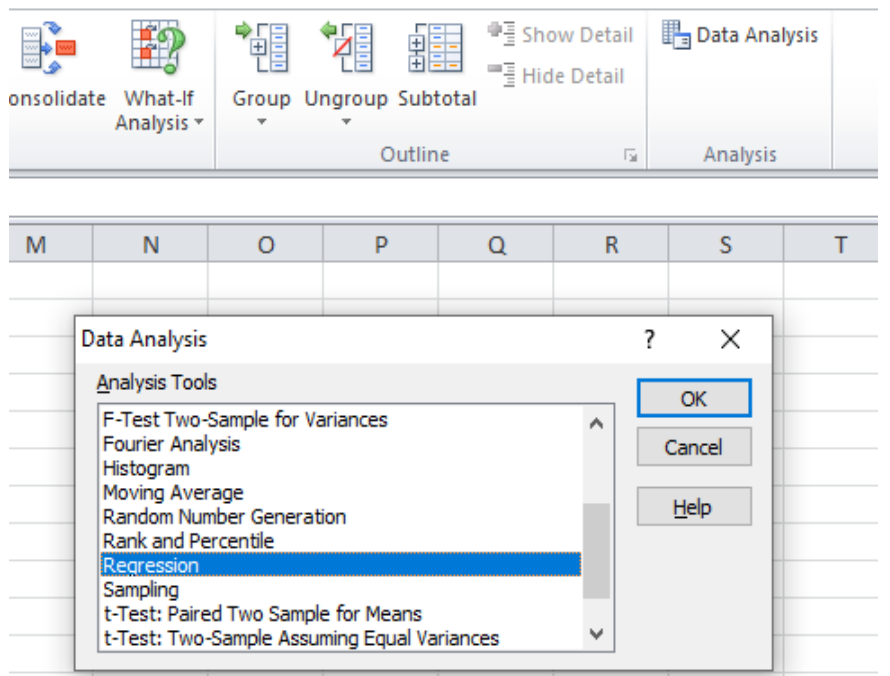

Figure 6. Regression computing in Excel

\section{CONCLUSIONS}

The knowledge of software applications is crucial for the textile creatives. The Erasmus+ OptimTex project was conceived, in order to support them with educational materials in software for e-textiles design of weaving, knitting, virtual prototyping of clothing, embroidery of e-textiles and experimental design. The educational modules are structured in a Problem-Based-Learning approach, with examples, theory, applications and quiz. An elearning instrument was programmed in HTML5 and JavaScript, in order to enable quick access to the educational content. The fifth educational module "Software for research experimental design” was prepared by the team of INCDTP - Bucharest. It follows several examples of experimental design plans, based on the plasma treatment of textiles for various functionalities. The complete educational materials are already available on www.optimtex.eu. Intensive study programs with 60 students and multiplier events with 115 professionals will be organized in the second project's year.

\section{ACKNOWLEDGEMENTS}

The authors would like to express appreciation for the support of the funding received by the Erasmus+ National Agency in Romania, ANPCDEFP [Project Number $=2020-1$ RO01-KA203-079823]. This project has been funded with support from the European Commission.

\section{REFERENCES}

[1] Van Langenhove, L., Smart textiles for protection: an overview, In: Chapman R.A., Editor: Smart textiles for protection, Woodhead Publishing Limited, 2013. 3-33, ISBN 978-0-85709-762-0

[2] Çelikel, D.C., Smart E-Textile Materials, In: Advanced Functional Materials, edited by Tasaltin, N., Nnamchi, P.S., Saud, S., In: IntechOpen, 2020, https://doi.org/10.5772/intechopen.92439

[4] Malengier, B., Radulescu, I.R., Blaga, M., Stjepanovic, Z., Design based learning in textiles for higher education, At: MCCSIS E-learning Conference, 2021, ISBN: 978-989-8704-29-0

[5] Radulescu, I.R., Ghituleasa, C., Visileanu, E., Almeida, L., Malengier, B., Stjepanovic, Z., Blaga, M., Dufkova, P., E-learning instruments for design based learning in textiles, At: The 17th eLearning and Software for Education Conference - eLSE, 2021

[5] Markham, T., Project Based Learning. Teacher Librarian, 2011, 39, 2, 38-42 
[6] Dolmans, D., How theory and design-based research can mature PBL practice and research, In: Advances in Health Sciences Education, 2019, 24, 879-891, https://doi.org/10.1007/s10459-01909940-2

[7] Titu, M., Oprean, C., Boroiu, A., Cercetarea experimentala aplicata in cresterea calitatii produselor si serviciilor (Experimental design applied to increasing quality of products and services), In: AGIR Publishing House, 2011

[8] Sartorius Stedim Data Analytics, Version 12, User Guide to MODDE, Available at: https://blog.umetrics.com/hubfs/Download\%20Files/MODDE\%2012.0.1\%20User\%20Guide.pdf

[Accessed on June 2021] 